\title{
Research Progress of Low Temperature Plasma Technology to Treat Sulfur-containing Malodorous Gas
}

\author{
Du Zhehua ${ }^{1}$ \\ ${ }^{1}$ Wuhan Second Ship Design and Research Institute, 430205 Wuhan, China
}

\begin{abstract}
This paper briefly discusses the source, harm and removal methods of sulfur-containing malodorous gas. At this stage, the main methods for treating sulphur-containing malodorous gases are physical, chemical and biological methods. In contrast, low temperature plasma technology combines the advantages of physical, chemical and biological methods, and can effectively overcome the disadvantages of traditional processes. Through the comparison of various methods, the advantages of low temperature plasma treatment of sulfur-containing malodorous gas are summarized, and the corresponding removal mechanism is proposed. The treatment progress and existing problems of using low-temperature plasma to remove sulfur-containing malodorous gas, especially hydrogen sulfide, carbon disulfide, methyl sulfide, methyl mercaptan and dimethyl disulfide, are comprehensively discussed. A new idea for the simultaneous removal of multi-component sulfur-containing malodorous gas by low temperature plasma is proposed. Compared with traditional methods, low temperature plasma technology has the advantages of simple process, strong applicability, easy operation, and low energy consumption in processing sulfur-containing malodorous gases. The treatment of sulfur-containing malodorous gas by low-temperature plasma technology needs further research.
\end{abstract}

\section{Introduction}

The direct emission of malodorous gas will not only endanger human health, but also pose a serious threat to the surrounding environment. It is mainly through the odor group such as sulfur, carbonyl group to stimulate olfactory cells[1-2]. Among many odorous gases, sulfurcontaining odorous gases are the most typical ones. According to Chinese regulations, there are 8 kinds of malodorous gases to be restricted, and 5 kinds of sulfur compounds. Sulfur-containing malodorous gases come from a wide range of sources, mainly from the corruption of animals and plants in the natural ecological environment, petroleum processing, various chemical production, storage and transportation processes. Under normal circumstances, the olfactory threshold of human smell for most malodorous substances is below $10^{-9}$, which far exceeds the minimum detection concentration of malodorous substances by analytical instruments and the allowable emission concentration of the factory. At this stage, the main methods for treating sulphurcontaining malodorous gases are physical, chemical and biological methods, as shown in Table 1. With the rapid development of science and technology, low temperature plasma technology came into being. In contrast, low temperature plasma technology combines the advantages of physical, chemical and biological methods, and can effectively overcome the disadvantages of traditional processes.
Table 1. The comparison of differednt methods to deal with sulfide odors.

\begin{tabular}{|c|l|l|}
\hline $\begin{array}{c}\text { Physical } \\
\text { and } \\
\text { chemical } \\
\text { methods }\end{array}$ & $\begin{array}{l}\text { advantages } \\
\text { High concentration } \\
\text { and high efficiency }\end{array}$ & $\begin{array}{l}\text { disadvantages } \\
\text { high investment cost, } \\
\text { complicated operation, } \\
\text { high energy } \\
\text { consumption, secondary } \\
\text { pollution, etc. }\end{array}$ \\
\hline & $\begin{array}{l}\text { Wide application } \\
\text { ange, simple } \\
\text { equipment, little } \\
\text { secondary } \\
\text { pollution, low } \\
\text { energy } \\
\text { consumption, etc. }\end{array}$ & $\begin{array}{l}\text { Slow speed, large area, } \\
\text { unstable processing } \\
\text { efficiency, etc. }\end{array}$ \\
methogical \\
meths
\end{tabular}

\section{The mechanism of action}

Low temperature plasma can be divided into glow discharge, corona discharge, dielectric barrier discharge, radio frequency discharge and microwave discharge according to different discharge methods. Although the forms of discharge are not the same, the mechanism of low-temperature plasma is similar. It can be expressed as that electrons obtain energy from the electric field. They move at extremely high speed in the electric field and collide with molecules during the movement. In one case, it acts directly with polluting gas, so that polluting gas

\footnotetext{
* Corresponding author: shunli878@163.com
} 
obtains energy and is excited, and is ionized and converted into other substances for removal. In the other case, other gas molecules are ionized to produce active ions. Due to the strong reactivity of the generated active ions, they interact with the polluted gas and convert the polluted gas into other substances.

The mechanism of removing sulphur-containing odorous gas by low temperature plasma is complex. Taking $\mathrm{H}_{2} \mathrm{~S}$ as an example, based on domestic and foreign research on the degradation of $\mathrm{H}_{2} \mathrm{~S}$ by lowtemperature plasma, it is currently believed that there are two main degradation pathways for $\mathrm{H}_{2} \mathrm{~S}$.

- High-energy electrons directly act on $\mathrm{H}_{2} \mathrm{~S}$ gas molecules[3].

$\mathrm{e}+\mathrm{H}_{2} \mathrm{~S} \rightarrow \mathrm{HS}+\mathrm{H}^{\cdot}+\mathrm{e}$

- High-energy electrons act on the intermediate active material. These electron-excited active substances and free radicals act on sulfur-containing odorous gas molecules or on the intermediate products of the decomposition of sulfur-containing odorous gas molecules[4].

$$
\begin{aligned}
& \mathrm{HS}+\mathrm{O}_{2} \rightarrow \mathrm{OH}+\mathrm{SO} \\
& \mathrm{N}_{2}+\mathrm{e}^{-} \rightarrow \mathrm{N}_{2}\left(\mathrm{~A}^{3} \Sigma_{\mathrm{u}}^{+}\right)+\mathrm{e}^{-} \\
& \mathrm{Ar}+\mathrm{e}^{-} \rightarrow \mathrm{Ar}\left({ }^{3} \mathrm{P}_{2}\right)+\mathrm{e}^{-} \\
& \mathrm{O}_{2}\left(\mathrm{X}^{3} \Sigma_{\mathrm{g}}^{-}\right)+\mathrm{e}^{-} \rightarrow \mathrm{O}_{2}^{-}\left({ }^{2} \Pi_{\mathrm{u}}\right)+\mathrm{O}^{-}\left({ }^{2} \mathrm{P}\right)+\mathrm{O}\left({ }^{3} \mathrm{P}\right) \\
& \mathrm{N}_{2}\left(\mathrm{~A}^{3} \Sigma_{\mathrm{u}}^{+}\right)+\mathrm{H}_{2} \mathrm{~S} \rightarrow \mathrm{N}_{2}+\mathrm{H}+\mathrm{HS} \\
& \mathrm{Ar}\left({ }^{3} \mathrm{P}_{2}\right)+\mathrm{H}_{2} \mathrm{~S} \rightarrow \mathrm{Ar}+\mathrm{H}+\mathrm{HS} \\
& \mathrm{H}_{2} \mathrm{~S}+\mathrm{O}\left({ }^{3} \mathrm{P}\right) \rightarrow \mathrm{OH}+\mathrm{HS} \\
& \left.\mathrm{HS}+\mathrm{O}^{3} \mathrm{P}\right) \rightarrow \mathrm{OH}+\mathrm{HS} \\
& \mathrm{HS}+\mathrm{O}_{2} \rightarrow \mathrm{OH}+\mathrm{SO} \\
& \mathrm{SO}+\mathrm{O}_{2} \rightarrow \mathrm{SO}_{2}+\mathrm{O}
\end{aligned}
$$

The purification mechanism of low-temperature plasma degradation of sulfur-containing waste gas is far from a clear understanding.

\section{Treatment of single-component sulfur-containing malodorous gas}

\section{1 $\mathrm{H}_{2} \mathrm{~S}$}

As the most common component in malodorous gas, $\mathrm{H}_{2} \mathrm{~S}$ has always been the focus of research on the removal of malodorous gas by low-temperature plasma. Techniques for $\mathrm{H}_{2} \mathrm{~S}$ degradation by various discharge modes have been developed, as well as plasma and other combined removal techniques.

The decomposition of $\mathrm{H}_{2} \mathrm{~S}$ to produce hydrogen is one of the main methods for treating hydrogen sulfide by plasma. Reddy et al.[5] use dielectric barrier discharge to decompose $\mathrm{H}_{2} \mathrm{~S}$ for hydrogen production. They investigated the effects of ground electrode material, discharge gap, dwell time, and $\mathrm{H}_{2} \mathrm{~S}$ concentration on decomposition efficiency and hydrogen production energy consumption, and explored the kinetic process of $\mathrm{H}_{2} \mathrm{~S}$ decomposition by dielectric barrier discharge. It was found that the material of the grounding electrode had little effect on the decomposition efficiency, but the other factors had great influence on the decomposition efficiency. And the longer the residence time, the lower the $\mathrm{H}_{2} \mathrm{~S}$ concentration, and the higher the efficiency of $\mathrm{H}_{2} \mathrm{~S}$ conversion to $\mathrm{H}_{2}$ and $\mathrm{S}$. When the discharge gap is
$3.5 \mathrm{~mm}$, the residence time is $6.8 \mathrm{~s}$, and the gas flow rate is $150 \mathrm{~mL} / \mathrm{min}$, the energy consumption for hydrogen production can be reduced to $1.6 \mathrm{eV} / \mathrm{molecule}$ at the lowest, but the conversion rate of $\mathrm{H}_{2} \mathrm{~S}$ is only $18 \%$ at this time. Although low energy consumption for hydrogen generation was achieved in this study, hydrogen production was relatively low, only $18 \%$, and the whereabouts of sulfur elements and by-products of reaction were not paid attention to. Nunnaly et al.[6] used gliding arc plasma to degrade $\mathrm{H}_{2} \mathrm{~S}$. By increasing $\mathrm{O}_{2}$ content in the mixture, the energy consumption of hydrogen production can be reduced and the decomposition rate of $\mathrm{H}_{2} \mathrm{~S}$ can be improved without reducing $\mathrm{H}_{2}$ production. When the flow rate of $\mathrm{H}_{2} \mathrm{~S}$ is $14 \mathrm{~L} / \mathrm{min}$ and the flow rate of $\mathrm{O}_{2}$ is $2.8 \mathrm{~L} / \mathrm{min}$, the minimum required SER for hydrogen production is 1.0 $\mathrm{eV} /$ molecule. The minimum SER required for $\mathrm{H}_{2} \mathrm{~S}$ decomposition is $0.43 \mathrm{eV} /$ molecule, which is very close to the optimal value in the study of low-voltage microdischarge.

In the study of $\mathrm{H}_{2} \mathrm{~S}$ removal from exhaust gas (especially low concentration $\mathrm{H}_{2} \mathrm{~S}$ ), plasma technology or combined plasma technology is used to convert $\mathrm{H}_{2} \mathrm{~S}$ into a form that is less toxic, non-toxic or easier to be purified by other ways. Huang et al.[7] used the combined technology of dielectric barrier plasma and ultraviolet-vacuum ultraviolet rays to treat $\mathrm{H}_{2} \mathrm{~S}$ and convert $\mathrm{H}_{2} \mathrm{~S}$ into $\mathrm{H}_{2} \mathrm{O}$ and $\mathrm{SO}_{4}^{2-}$. Studies have shown that factors such as $\mathrm{Kr}$ gas pressure, applied voltage, gas residence time, and $\mathrm{H}_{2} \mathrm{~S}$ inlet concentration significantly affect the removal efficiency of $\mathrm{H}_{2} \mathrm{~S}$. When applied voltage is $7.5 \mathrm{kV}$, retention time is $0.4 \mathrm{~s}$, inlet concentration is $27.1 \mathrm{mg} / \mathrm{m}^{3}$, and $\mathrm{Kr}$ pressure is $47 \mathrm{kPa}$, the removal efficiency of $\mathrm{H}_{2} \mathrm{~S}$ can reach $93 \%$, and the main reaction products are $\mathrm{H}_{2} \mathrm{O}$ and $\mathrm{SO}_{4}^{2-}$. The study only considered ultraviolet rays generated by the combination of $\mathrm{Kr}$ and $\mathrm{Br}_{2}$, and did not further study the comparison of the combination of other rare gases and halogens, and failed to effectively use the $\mathrm{H}$ and $\mathrm{S}$ elements in the recovery of $\mathrm{H}_{2} \mathrm{~S}$. Dang et al.[8] added metal oxide catalyst to dielectric barrier discharge plasma reactor, which can increase $\mathrm{O}_{3}$ content in the reactor and improve $\mathrm{H}_{2} \mathrm{~S}$ treatment efficiency. Finally, $\mathrm{H}_{2} \mathrm{~S}$ is oxidized to $\mathrm{S}$, $\mathrm{H}_{2} \mathrm{SO}_{3}$, and $\mathrm{H}_{2} \mathrm{SO}_{4}$. This study lacks catalyst selection conditions, preparation methods, and recycling plans, and does not pay attention to the whereabouts of $\mathrm{H}$ elements.

At present, the research direction of hydrogen sulfide removal by low temperature plasma technology is mainly focused on the decomposition of $\mathrm{H}_{2} \mathrm{~S}$ to produce hydrogen and the combination of plasma and other technologies, but most of the research is still in the experimental stage. The main research direction in the future is to further reduce the energy consumption required for decomposition and reduce the generation of secondary pollutants while improving the conversion rate of $\mathrm{H}_{2} \mathrm{~S}$. 


\section{$3.2 \mathrm{CS}_{2}$}

$\mathrm{CS}_{2}$ is an organic sulfur compound, which can be converted into $\mathrm{H}_{2} \mathrm{~S}$ and other substances under certain conditions. Because $\mathrm{CS}_{2}$ may be accompanied by the generation of a variety of by-products in the different concentrations, it is more complex than $\mathrm{H}_{2} \mathrm{~S}$ removal. At present, some achievements have been made in the removal of $\mathrm{CS}_{2}$, but there are still many problems to be further explored.

Yan et al.[9] used DC corona discharge plasma to treat $\mathrm{CS}_{2}$. With the increase of input energy, the removal effect of $\mathrm{CS}_{2}$ is obvious. When the input energy reaches $230 \mathrm{~J} / \mathrm{L}$, the removal efficiency of $\mathrm{CS}_{2}$ reaches $90 \%$. It was found in the experiments that the short-term presence of active substances (free radicals) was more important than the long-term presence of active substances in the conversion process of $\mathrm{CS}_{2}$.

Tsai et al.[10] used RF discharge plasma to decompose $\mathrm{CS}_{2}$ into solid sulfur in the low-oxygen environment. There was no elemental sulfur formation in the absence of oxygen and in the oxygen-rich condition $\left(\mathrm{V}\left(\mathrm{O}_{2}\right) / \mathrm{V}\left(\mathrm{CS}_{2}\right)=3\right)$. When $\mathrm{V}\left(\mathrm{O}_{2}\right) / \mathrm{V}\left(\mathrm{CS}_{2}\right)=0.6$ and input power was $90 \mathrm{~W}, 76.9 \%$ of $\mathrm{CS}_{2}$ was converted into elemental sulfur.

In addition to corona and radio frequency discharge, plasma combined technology is also used in the treatment of $\mathrm{CS}_{2}$. Zhu et al.[11] used the combined technology of dielectric barrier discharge low temperature plasma and $\mathrm{MnO}_{2}$ catalyst to treat $\mathrm{CS}_{2}$. The results showed that, under the combined action of DBD and $\mathrm{MnO}_{2}$ catalyst, $\mathrm{CS}_{2}$ is $10 \%$ more efficient than DBD alone. However, there is no difference between $\mathrm{CS}_{2}$ products produced by the two methods, which both contain $\mathrm{CO}, \mathrm{CO}_{2}, \mathrm{COS}$ and $\mathrm{SO}_{2}$. Fang et al.[28] designed a combined DBD plasma-photolysis technology to remove $\mathrm{CS}_{2}$. This is $20 \%$ more efficient than DBD plasma alone. The main reason is that $207 \mathrm{~nm}$ ultraviolet light produced by $\mathrm{KrBr}^{*}$ excited by the discharge in the DBD reactor is absorbed and decomposed by $\mathrm{SC}_{2}$.

\subsection{Dimethyl sulfide}

Dimethyl sulfide is a common organic sulfur odor pollutant. The decomposition products are mostly complex sulfides. Chen et al.[12] used micro-plasma to treat dimethyl sulfide with Ar gas as a carrier gas. The effects of residence time and electrode number on the degradation of dimethyl sulfide were investigated, and the main products were analyzed. The treatment efficiency of dimethyl sulfide with two pairs of electrodes is higher than that of a single pair of electrodes. Although a good purification effect has been achieved in the experiment, the energy consumption is too high and the by-products are too complex.

Chen et al.[13] used wire-barrel pulsed discharge plasma to treat dimethyl sulfide. The effects of different equilibrium gases, humidity, and oxygen content on the degradation of dimethyl sulfide were investigated. Experiments showed that the breakdown voltage of dimethyl sulfide in Ar atmosphere was lower than in $\mathrm{N}_{2}$.
Moreover, the removal efficiency of methyl sulfide in Ar atmosphere was much higher than that of $\mathrm{N}_{2}$ carrier gas.

Wei et al.[14] used biological drip filtration and plasma collective combination technology to treat methyl sulfide. In this method, methyl sulfide is oxidized to simple compounds such as methanol and COS, and the intermediate and methyl sulfide are oxidized to sulfate, water and $\mathrm{CO}_{2}$ in the biological process without any other by-products. Chen et al.[15] degraded methyl sulfide by activated carbon adsorption and dielectric barrier discharge. It was found that in addition to adsorption, activated carbon also had a significant synergistic purification effect with plasma.

\subsection{Methyl mercaptan}

Methane mercaptan is a common organic sulfur malodorous gas in petroleum processing enterprises. However, there are few studies on the treatment of methyl mercaptan by low temperature plasma technology, and the progress is relatively slow. $\mathrm{Li}[16]$ treated methyl mercaptan in a plasma reactor with nonthermally strong medium. It was found that voltage relative to residence time and initial concentration had the greatest effect on the decomposition efficiency of methyl mercaptan.

Tsai et al.[17] mainly investigated the effect of $\mathrm{O}_{2}$ content on the degradation of methyl mercaptan, as well as the degradation products and reaction pathways using $\mathrm{RF}$ plasma. In the presence of oxygen, the degradation products of methyl mercaptan included $\mathrm{SO}_{2}, \mathrm{CS}_{2}$, OCS, $\mathrm{CO}, \mathrm{CO}_{2}, \mathrm{CH}_{4}, \mathrm{C}_{2} \mathrm{H}_{4} \mathrm{C}_{2} \mathrm{H}_{2}, \mathrm{H}_{2}, \mathrm{H}_{2} \mathrm{O}, \mathrm{HCOH}$, and $\mathrm{CH}_{3} \mathrm{OH}$. Czernichowski[18] used gliding arc discharge plasma to treat methyl mercaptan. When the voltage reached $5 \mathrm{kV}$ and flow rate was $70 \mathrm{~m}^{3} / \mathrm{h}$, methyl mercaptan removal efficiency was close to $100 \%$.

\subsection{Dimethyl Disulfide}

As a widely used catalyst in petroleum industry, dimethyl disulfide is one of the eight key odor monitoring substances. There are few reports about the treatment of dimethyl disulfide exhaust gas by low temperature plasma. Hatakeyama et al.[19] used RF plasma to photolyze dimethyl disulfide in the air. The main products were found to be $\mathrm{CH}_{3} \mathrm{~S}$ and $\mathrm{CH}_{3} \mathrm{SOH}$. Xia et al.[20] used dielectric barrier discharge plasma to degrade dynamic dimethyl disulfide exhaust gas. The conversion rate of dimethyl disulfide under different residence time, inlet gas concentration and applied voltage was studied. Due to its own characteristics, synergistic effects tend to occur. While different component gases are removed at the same time, the production of by-products is also reduced.

\section{Treatment of multi-component sulfur- containing malodorous gas}

The composition of industrial waste gas is more complicated, and there are often multi-component sulfurcontaining malodorous gases. It is imperative for low 
temperature plasma to simultaneously remove multicomponent sulfur-containing odorous gases. Generally, the sulfur element in organic sulfur and hydrogen sulfide has strong reducibility.

Tsai et al.[21] studied the synergistic purification of $\mathrm{CS}_{2}$ and $\mathrm{SO}_{2}$ using $\mathrm{RF}$ discharge plasma. They found that when $\mathrm{V}(\mathrm{CS} 2) / \mathrm{V}(\mathrm{SO} 2)=2$, the conversion rate of both reached the maximum over $95 \%$.At this time, most of $\mathrm{S}$ element formed elemental sulfur.

$\mathrm{Lu}$ et al.[22] used gliding arc plasma to treat the mixed gas of $\mathrm{NH}_{3}$ and $\mathrm{H}_{2} \mathrm{~S}$ in the waste gas of municipal sewage sludge drying. They found that applied voltage and air velocity can significantly affect treatment effect. When applied voltage was above $11 \mathrm{kV}$ and gas flow rate was $4.72 \mathrm{~m} / \mathrm{s}$, treatment effect is close to $100 \%$. The energy consumption of simultaneous degradation of $\mathrm{NH}_{3}$ and $\mathrm{H}_{2} \mathrm{~S}$ was $38 \%$ lower than that of degradation alone. The presence of $\mathrm{NH}_{3}$ can significantly inhibit the production of $\mathrm{SO}_{2}$. The presence of $\mathrm{H}_{2} \mathrm{~S}$ also reduces the production of $\mathrm{NO}$ and $\mathrm{HCN}$.

Yan et al.[23] used pulsed corona plasma to treat sulfur-containing exhaust gas. When discharge power is $5.6 \mathrm{~W}$, the removal efficiencies of $\mathrm{H}_{2} \mathrm{~S}$, methyl mercaptan, and methyl sulfide are $90 \%, 69 \%$, and $52 \%$, respectively. When activated carbon fiber was added to the back end of the reactor, pollutant removal efficiency reaches $98 \%$.

\section{Conclusion}

Compared with traditional methods, low temperature plasma technology has the advantages of simple process, strong applicability, easy operation, and low energy consumption in processing sulfur-containing malodorous gases. At present, a lot of work has been done on the treatment of sulfur-containing odorous gas by low temperature plasma technology at home and abroad, and some achievements have been made. However, the current research mainly focuses on the removal of single-component inorganic sulfur malodorous gas, and there is less research on the synergistic purification of organic sulfur malodorous gas and multi-component sulfur-containing malodorous gas. At present, low temperature plasma treatment of sulfur-containing malodorous gases (especially organic sulfur malodorous gases) has serious secondary pollution by-products. Therefore, future research is mainly carried out from the following aspects.

- The research on the mechanism of low-temperature plasma treatment of sulfur-containing malodorous gas should continue to be further studied. Finally, the high added value of elemental sulfur can be recovered and utilized while degrading sulfur-containing odorous gases.

- The combined treatment technology of plasma and catalyst or biological process should be developed vigorously. The control of organic sulfur odor gas reaction byproducts should be paid more attention.

- Research on the simultaneous removal of multicomponent sulfur-containing malodorous gas by lowtemperature plasma should be strengthened. By strengthening the synergy between different gases, it can achieve the collaborative purification of multi- component sulfur-containing malodorous gases with different concentrations.

- The existing production process should be improved. By improving resource utilization efficiency, the emission of pollutants can be reduced at the source.

\section{References}

1. Z. Fu, P.J. He, G.J. Li, Environmental Sanitation Engineering, 12, 3(1997)

2. G.J. Zhang, K. Li, Q. Li, Materials Review, 29,137 (2015)

3. G.B. Zhao, S. John, J.J. Zhao, Chem. Eng. Sci., 62, 2216 (2007)

4. Y. Itikawa, J. Phys. Chem. Refference Date, 38, 1 (2009)

5. E.L. Reddy, J. Karuppiah, J. Energy chem., 22, 382 (2013)

6. T. Nunnally, K. Gutsol, A. Rabbitovic, Int. J. Hydrogen Energy, 39, 12480 (2014)

7. L. Huang , L.Y. Xia, X.X. Ge, Chemosphere, 88, 229 (2012)

8. X.Q. Dang, J.Y. Huang, L. Kang, Energy Procedia, 16, 856 (2012)

9. X. Yan, Y.F. Sun, J. Hazard Mater., 261, 669 (2013)

10. C.H. Tsai, W.J. Lee, C.Y. Chen, Ind. Eng. Chem. Res., 41, 1412 (2002)

11. C.Z. Zhu, J. Lu, X.H. Wang, Plasma Chem. Plasma Process, 33, 569 (2013)

12. H.H. Chen, C.C. Wen, J.D. Liao, J. Hazard Mater., 185, 201 (2012)

13. J. Chen, Q.F. Su, H. Pan, Chemosphere, 75, 261 (2009)

14. Z.S. Wei, H.Q. Li, Bioresource Technol., 146, 451 (2013)

15. J. Chen, Y. Weng, Journal of Chemical Engineering of Chinese Universities, 25, 495 (2011)

16. X.J. Li, Environmental Protection of Chemical Industry, 22, 125 (2002)

17. C.H. Tsai, W.J. Lee, C.Y. Chen, Ind. Eng. Chem. Res., 40, 2384 (2001)

18. A. Czernichowski, Oil Gas Sci. Technol., 54, 337 (1999)

19. S. Hatakeyama, H. Akimoto, J. Phys. Chem., 87, 2387 (2001)

20. L.Y. Xia, H.J. Fang, Acta Scientiae Circumstantiae, 27, 1000 (2007)

21. C.H. Tsai, Y.F. Wang, Energy Fuels, 18(2), 465 (2004)

22. S.Y. Lu, L. Chen, Chemosphere, 117, 781 (2014)

23. N.Q. Yan, Z. Qu, Ind. Eng. Chem. Res., 45, 6420 (2006) 